\title{
Erratum to: Demonstration of Neuron-Glia Transfer of Precursors for Gaba Biosynthesis in a Co-Culture System of Dissociated Mouse Cerebral Cortex
}

\author{
Renata Leke - Lasse K. Bak · Arne Schousboe • \\ Helle S. Waagepetersen
}

Published online: 2 October 2009

(C) Springer Science+Business Media, LLC 2009

\section{Erratum to: Neurochem Res (2008) 33:2629-2635 \\ DOI 10.1007/s11064-008-9814-6}

Unfortunately Fig. 4 of this article was published wrongly. Correct version of Fig. 4 is as given below.
The online version of the original article can be found under doi:10.1007/s11064-008-9814-6.

R. Leke · L. K. Bak · A. Schousboe $(\bowtie) \cdot$ H. S. Waagepetersen Department of Pharmacology and Pharmacotherapy, Faculty of Pharmaceutical Sciences, University of Copenhagen,

Universitetsparken 2, 2100 Copenhagen, Denmark

e-mail: as@farma.ku.dk

\section{R. Leke}

Department of Biochemistry, ICBS, Federal University of Rio Grande do Sul, Porto Alegre, RS, Brazil
Also in page 2632, second column, line 3 should read 'significantly lower at the low extracellular glutamine'. Page 2634, first column, line 33 should read 'concentration, although that of glutamate increased by'.

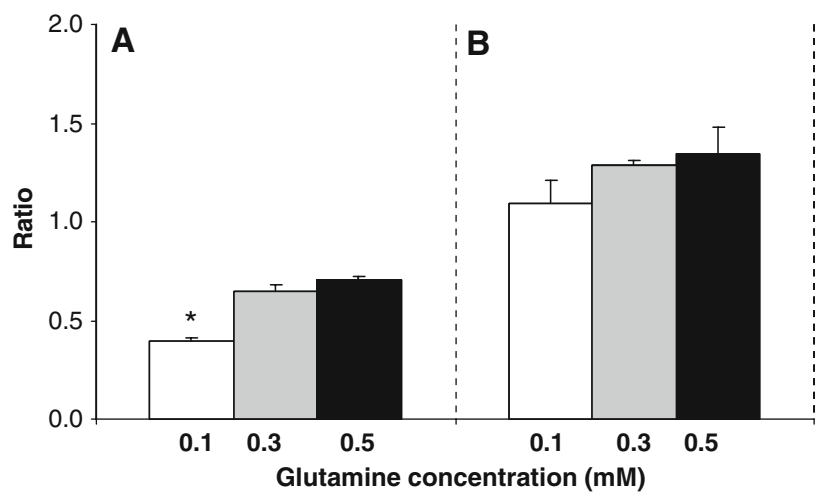

Fig. 4 Ratios of $M+5$ (glutamate, $A$ ) or $M+4$ (GABA, B) divided by $\Sigma \mathrm{M}+3, \mathrm{M}+2, \mathrm{M}+1$ and $\Sigma \mathrm{M}+2, \mathrm{M}+1$, respectively in cultures of dissociated mouse cerebral cortex. Cultures were prepared as described in "Experimental Procedures" and subsequently incubated for $2.5 \mathrm{~h}$ in media containing $\left[\mathrm{U}_{-}{ }^{13} \mathrm{C}\right]$ glutamine (concentrations $0.1 \mathrm{mM}$ (white bars), $0.3 \mathrm{mM}$ (grey bars) and $0.5 \mathrm{mM}$ (black bars)). Ratios were determined as detailed in "Experimental Procedures". Results are averages \pm S.E.M. of $4-5$ cultures. The asterisk indicates statistically significant differences determined by ANOVA (see "Experimental Procedures") from $0.3 \mathrm{mM}$ or $\left.0.5 \mathrm{mM} \mathrm{U}-{ }^{13} \mathrm{C}\right]$ glutamine $(P<0.001)$ 